\title{
Colon Serrated Adenocarcinoma
}

National Cancer Institute

\section{Source}

National Cancer Institute. Colon Serrated Adenocarcinoma. NCI Thesaurus. Code C96486.

A rare, invasive colon adenocarcinoma characterized by the presence of a malignant infiltrate with serrated glandular architecture. 